DOI 10.37882/2223-2982.2020.07.40

\title{
КОГНИТИВНЫЕ ОСНОВЫ ОШИБОК В УПОТРЕБЛЕНИИ ГЛАГОЛА У ИЗУЧАЮЩИХ РУССКИЙ ЯЗЫК КАК ИНОСТРАННЫЙ
}

\section{COGNITIVE BASIS OF ERRORS IN VERB USAGE MADE BY LEARNERS OF RUSSIAN AS A FOREIGN LANGUAGE}

A. Schelokova

Summary: The article highlights the results of a study of the mistakes of Chinese residents in spoken and written language, a comparative analysis of the grammatical expression of the verb in Russian and Chinese languages showed that the verb categories of these languages not relevant, and inconsistent grammatical signs of the Russian verb, such as the person, number and gender of them not at all represented in Chinese. This fact leads to the substitution of the elements of the synthetic expression of the verbal categories of the Russian language. Also, in the analyzed examples the lexical substitution is indicative, based on the polyvalency of the Russian verb, which is reflected in the prepositional case system. The analysis carried out makes it possible to say that the phenomenon of substitution, in turn, forms two types of errors in the speech of students of the Russian language as foreign: structural and destructive.

Keywords: category, verb, error, substitution, Russian, Chinese

\author{
Щелокова Алена Александровна \\ преподаватель, Уральский государственный \\ университет путей сообщения, Екатеринбург \\ aschelokova@usurt.ru
}

Аннотация: Статья освещает результаты проведенного исследования ошибок китайских резидентов в устной и письменной речи. Сравнительный анализ грамматического выражения глагола в русском и китайском языках показал, что глагольные категории данных языков не релевантны, причем непостоянные грамматические признаки русского глагола, такие как лицо, число и род из них совсем не представлены в китайском языке. Данный факт приводит к субституции элементов синтетического выражения глагольных категорий русского языка. Также в анализируемых примерах показательна лексическая субституция, основанная на поливалентности русского глагола, отражающейся в предложно-падежной системе. Проведенный анализ дает возможность утверждать, что явление субституции в свою очередь формирует в речи изучающих русский язык как иностранный ошибки двух типов: структурную и деструктивную.

Ключевые слова: категория, глагол, ошибка, субституция, русский язык, китайский язык.

ческие особенности категоризации глагольной систем (русской и китайской).

Н.Н. Болдырев указывает, что категоризация есть динамический процесс установления связи между предметом мысли и языковым знаком; мыслительный (когнитивный) акт, состоящий в признании и актуализации существующих норм категориального членения смыслового континуума посредством языка, а также формирование новых концептуальных связей: соотнесение известных категорий с неизвестными, вызывающее перекатегоризацию языковых единиц. Это способ структурирования передаваемой и получаемой информации [1, с. 5]. Необходимо оговориться, что категоризация обладает в силу человеческого мышления двумя очень важными аспектами, раскрытыми одной из основоположников исследования когнитивной категоризации Э. Рош. Ученый говорит, при категоризации, с одной стороны, признаки, обозначающие концепт и влияющие на образование категорий, обладают разной значимостью, с другой стороны, представители категорий обладают разным набором этих признаков, различаясь по одним и объединяясь по другим признакам [2, с. 2]. Первый аспект непосредственно релевантен при изучении иностранного языка: у обучаемого в любой момент (особен- 
но на начальном этапе) возникает нужда выстраивать категорию из элементов, не обладающих в материи своего родного языка большой значимостью, или вообще не обладают значимостью (например, китайским резидентам приходится понять, что род в русском языке имеет основополагающее значение, нежели в китайском языке). Несмотря на значимость / незначимость, можно выделить универсальные принципы, которые характерны и для естественной, так и искусственной (при изучении неродного языка) категоризации.

Мы согласимся с К. М. Абишевой, которая выделяет пять основных универсальных принципов категоризации, отражающих основной «набор» признаков, характерных для глагольной системы любого языка [2, с. 23-25].

Первый - принцип прототипичности, по которому обладание представителями категорий разного набора признаков, где по одним признакам представители объединяются, одновременно различаясь по другим. Например, глаголы режет и пилит имеют общие категории времени, наклонения, числа и лица, но разделены категорией спряжения.

Второй принцип основан на понимании факта нестрогости категорий, по которой отнесение представителя к определенной категории (классу, разряду, объединению) происходит в тех случаях, когда объект обнаруживает лишь некоторые из признаков, формирующих представление о типичных представителях данной категории. Например, употребление в функции императива словосочетаний изъявительного наклонения в форме настоящего и прошедшего времен: Встаем и делаем! и Встали и сделали!

Третий принцип формируется на понимании множественности (или разнородности) оснований категоризации, которая основывается на субъективации в познании мира или условном разделении категорий на «природные» и «семантические» [2]. Ср.: глагол «играть» в русском и китайском (玩) языках тождественны только в 'забавляться', далее: играть в футбол - пинать мяч 踢足 球, играть в шахматы - опускать шахматные фигуры 下棋, играть на гитаре - щипать струну 弹;

Четвертый принцип - принцип континуальности («вещецентризм», на основе которого строится модель: вещь первична, признаки (свойства, отношения) - вторичны. Например, «звонят» - ожидаемая реакция, сопровождаемая переживанием намерения, которое невербально, пойти и открыть дверь [4, с. 104].

И, наконец, пятый принцип построен на дифференциации градуированности по родовидовым отношениям. Формирование значения небольшой меры проявления действия за счет приставки по - (= «немного»): поиграть, посидеть, почитать т.д.

Итак, процесс категоризации универсален, но носит принцип «нужности / ненужности» в своих естественных «условиях», в условиях «искусственных» (при изучении иностранного языка, в частности русского) пути категоризации оказываются разными, что отражается, прежде всего, в «оформлении» глагола. Например, исследователи указывают на такие национально-специфические особенности глагольной категоризации в русской лингвокультуре, как аспектуальность, видовременная система $[5,6,7,8]$, семантика $[9,10,11,12.13,14]$, а также особого внимания заслуживает словообразовательная категория глагола в русском языке $[15,16]$, выявляющая несамостоятельность основы глагола, нестандартность окончаний, нечеткую морфемную границу.

Таким образом, категоризация глагола в русском языке представлена следующими системообразующими категориями: лексическая, грамматическая, словообразовательная, взаимодействие которых обеспечивает формирование его категориального значения в процессе построения высказывания.

Определяя категоризацию глагола и ее составляющих в китайском языке, ученые $[17,18,19,20]$ указывают на существенные различия выражения глагольного значения в речи в китайском и русском языках, объясняя это отнесением данных языков к противопоставленным типам существующих классификаций: изолирующий и флективный; аналитический и синтетический; «язык обладания» (have-language) и «язык бытия» (be-language). Принимая данный факт во внимание, но, исследуя современное состояние китайского языка, Ч. Цзин утверждает, что увеличение флективных (например, двойных глаголов) и агглютинативных (аффиксов) элементов дает возможность утверждать, что китайский язык находится на фазе перехода к флективному типу [21, с. 91]. Но, самой типичной чертой китайского языка по сравнению с русским, по мнению китаистов, является отсутствие словоизменения, которую можно продемонстрировать на примере глаголов говорить - сказать (shuo): я говорю - wo shuo, ты говоришь - ni shuo, он говорит - ta shuo, он вчера говорил - ta zuo tian shuo, он сейчас говорит - xian zai shuo, он завтра скажет - ming tian shuo.

Особого внимания заслуживают работы по сравнительному (сопоставительному) анализу категоризации глагола в русском и китайском языках [22, 23, 24]. Авторы приходят к общему мнению, что в китайском языке, как языке изолирующего типа, характерным признаком которого является отсутствие словообразовательных морфем, а, следовательно, и словообразовательной (деривационной) категории глагола, «единодушно не признают наличия ... грамматических категорий глагола, таких как лицо, время и наклонение» [24, с. 111]. Иссле- 
дования посвящены также категории времени, вернее ее формальному отсутствию в китайском языке, то есть глаголы и глагольные сочетания не могут отражать какой-либо временной план. Эту функцию выполняют наречия, служебные слова, имена темпоральной семантики, а также контекст.

Различие выражения основных глагольных категорий осложняются и внутрилингвистическими интерферирующими факторами русского языка, такими, как отсутствие унифицированных показателей глагольного вида; употреблением глагольной лексемы в разных лексических вариантах с изменением глагольного управления (учить кого? и учить что?); переносным употреблением видовременных форм.

Соответственно, можно выделить существенные различия в функционировании основных элементов глагольной категоризации в русском и китайском языках: глагольная категоризация в русском языке представляет собой систему противопоставленных рядов словоформ, образующих замкнутую систему грамматических значений; в китайском языке грамматическое значение глагола определяется правилами сочетаемости и композиции и подчиняется им; в русском языке при выражении грамматического значения морфологическая форма первична, а синтаксическая вторична, в китайском языке в качестве основного средства выражения выступает синтаксическая форма, а морфологическая форма становится дополнительным. При этом лексическая категория приоритетна в обоих языках по сравнению с грамматической, отличие данного аспекта в китайском языке - привлечение функциональных слов для реализации смысла высказывания.

Говоря о категории аспектуальности, в современных исследованиях по сравнительному анализу глагольной категоризации для характеристики глаголов в китайском языке этот термин считается полнозначным (включающим в себя, в отличие от термина «вид» в русском языке: вид, способ действия, неглагольные лексические и синтаксические показатели), то ряд служебных элементов, аналогичных выражению темпоральности, квалифицируются как ее грамматическое выражение [25, с. 305]. Но, применительно к русскому языку, в котором преобладают синтетические формы выражения грамматических значений, время и вид глагола, или его темпоральность и аспектуальность, передаются в китайском языке не грамматически, а лексически. Соответственно, нельзя говорить, что категория аспектуальности отсутствует в китайском языке. Однако в отличие от русского языка категория аспектуальности выражается - лексически - при помощи специальных лексикализированных компонентов, стоящих после глагола и выражающих совершенное или несовершенное грамматическое значение. Эти компоненты и являются показателями видовой принад- лежности данного глагола в определенном контексте. Поэтому русский глагол воспринимается китайскими резидентами как часть речи, описывающая какое-либо действие, при этом другие категориальные признаки оказываются не значительными для них. Если говорить о лексических несоответствиях, которые могут повлиять на правильность употребления китайскими резидентами русского глагола возникают на уровне функционирования антонимичных категорий акциональность и статальность. Как показывают наблюдения над речевыми ошибками китайских резидентов, изучающих русский язык, последние не могут определить акциональный или статальный характер русского глагола.

По словам Н.Н. Болдырева, категория акциональности формируется на основе концептуализации говорящими такими внеязыковыми элементами, как ориентированность действия на субъект, наличие у последнего волитивности (он должен обладать собственной энергией для осуществления действия), и контроль над процессом [2, с. 23-25]. С другой стороны, акциональность формируется тем, что субъект воздействует на объект, контролирует его и ждет получение результата по этому действию. Соответственно, говорящий отражает сопутствующие элементы каждого действия: локализованность во времени и пространстве, а также фазовость различного формата. Статальность, наоборот, отражается событиями, в которых активность субъекта и воздействие на объект никак не проявляются, то есть не имеют референции (нереферентная активность и нереферентное воздействие). Реализация соответствующих концептуальных признаков высказывания обеспечивается за счет использования определенных грамматических форм: глаголы действия - актуальное время, императив, пассив, рефлексив; статальные глаголы - форма неопределенного времени. Реализация признаков, не свойственных системному значению глагола приводит к перекатегоризации [26, с. 47].

Несоответствие базовых категорий глагола в родном для китайского резидента языке по сравнению с изучаемым им русским языком приводит к ошибкам, главной, как свидетельствует статистический анализ, является ошибка субституции, которая заключается в ошибочной подмене одного элемента другим в результате несовпадения (и/или отсутствия) той или иной категории. При этом необходимо отметить, что субституция бывает двух видов: лексическая и грамматическая. Исходя из того принципа, что лексическая категория приоритетна, стоит говорить, что на уровне понимания (а это важно для иностранца, так как для него главное быть понятым) лексическая ошибка оказывает деструктивный характер, а грамматическая ошибка - конструктивный.

В отечественном и зарубежном языкознании существует несколько подходов к изучению к субституции 
[28, 29, 30, 31, 32, 33, 34 и др.]. Так, например Л. Блумфилд определяет субституцию как замещение одной единицы другой, имеющей значение класса слов [28, с. 270]; Л. В. Артюшкина пишет, что считать субституцией следует «замену одного знака, неприемлемого по каким-либо причинам, другим, семантически и/или стилистически модифицированным» [35]; по М.Ф. Лукину - «образование словоформами какой - либо части речи своих вторичных форм (трансформ) и употребление их в качестве субститутов - заместителей конкретных или потенциальных слов других частей речи» [36, с. 50]. Р. Краймз описывает субституцию как анафорическое явление, при котором десемантизированные (служебные) слова, наполненные смыслом посредством ближайшего контекста, противопоставлены знаменательным словам с лексическим значением отождествления или указания, осуществляющим повторную номинацию уже упомянутого объекта; при этом разделяет анафорическую субституцию на два вида: замещение и репрезентацию [37].

Сформулированные учеными толкования термина «субституция» обеспечивают возможность определения классификационных видов проявления этого механизма в языке. Ц. Гун придерживается принятых в русистике двух основных направлений субституции, в ее узком и широком понимании:

1. перевод слова (или основы слова) из одной части речи в другую;

2. перенос любой языковой формы, например, транспозиция времен (использование настоящего времени вместо прошедшего / будущего) [38, с. 20].

Опираясь на исследования в данной области, можно говорить о выделении следующих видов субституции в зависимости от области ее реализации:

1. лексическая субституция (синонимическая замена (полное или частичное совпадение значений); антонимическая замена (предполагает противоположность выражаемых словами понятий);

2. замена на основе гипо-гиперонимических отношений (основана на родовидовых отношениях); лексическая замена на основе прецедентной информации; замена компонентов паронимами) [39];

3. словообразовательная (морфемно-морфемная, морфемно-сегментная, сегменто-морфемная, сегменто-сегментная) [32];

4. фонетическая (различные фонемы: изменение или потеря значения слова, факультативные варианты одной фонемы: значение слов не изменяется) [34, с. 76],

5. грамматическая (преобразование грамматической единицы любого уровня (словоформа, часть речи, член предложения, предложение определенного типа) в оригинале на единицу с иным грамматическим значением) [40, с.180].
Считается, что субституция не является ошибкой, если соблюдается следующая аксиома: исходная единица и субститут должны быть взаимно заменимы во всех высказываниях без изменения выражаемого смысла [41, c. 91].

Итак, рассмотрим грамматико-конструктивные и лексико-деструктивные ошибки, построенные на механизме субституции, возникшей в результате речепорождения китайских резидентов. В данном случае мы имеем следующие типы грамматических ошибок:

1. Субституция на уровне видовых форм: $\mathrm{HCB} \leftrightarrow \mathrm{CB}$. Ср.: Сейчас я буду лечь спать / Я напишу статью и отдыхаю / Повторяйте, что Вы сказали? / Борис решил задачу 2 часа / Когда я отдыхаю, я смотрел телевизор. В данном случае ошибки возникают в результате явного недопонимания категории аспектуальности, эксплицитно не представленной в китайском языке.

2. Субституция на уровне личных форм: инфинитив $\leftrightarrow$ личная форма глагола. Ср.: Я вчера ехать cnamb.

Косвенно доказательство тому, что аспектуальность не важна, и она выражается лексическим путем - это несогласование видовременных форм со словами - маркерами. Китайцы считают, что их будет достаточно, чтобы быть понятым (как в китайском языке). Получается, что у китайцев идет гиперолизация русских слов - маркеров. Ср.: Моя мама часто купит фрукты / Мы скоро будем ходить обедать / Когда я отдыхаю, я посмотрел телевизор / Мария попросила, где находится библиотека.

Ярким примером важности слов-маркеров выступает факт субституции не только видовых форм, но и временных. Ср.: Вчера Катя будет играть на пианино.

3. Субституции подвергаются также категория числа и лица. В данном случае характерными являются два типа ошибок:

- на уровне личных форм: инфинитив $\leftrightarrow$ личная форма: А потом мы вернуться в общежитие / $\mathrm{OH}$ находиться в Екатеринбург / Я решил пообедал дома.

- на уровне путаницы личных форм: личная форма $\leftrightarrow$ личная форма. То есть, идет взаимное исключение видовых форм. Ср.: Маша и Лена часто слушаете музыку / Кто говорили по телефону? / А я живут в общежитии.

Перейдем к рассмотрению деструктивной ошибки, при которой смысл всей фразы теряется полностью, и которая также является результатом действия субституции. В данном случае субституция действует качественно со знаком «минус» (отрицательная субституция), так как влияет на смысл (то есть его разрушает или вводит 
адресата в заблуждение). Категоризация аспектуальности, времени, лица и числа не имеет большого значения, даже если эти категории выражены правильно. На первый план выдвигаются ошибки в глагольном управлении, то есть такие ошибки показательны в том, что в китайском языке отсутствуют (или выражены слабо) такие категории, которые в русском языке отражаются в предложной системе. В данном случае мы имеем лексическую субституцию, основанную на поливалентностой особенности русского глагола, которая может отсутствовать в китайском языке. В формальном плане ошибка возникает в результате:

1. упущения предлога, думается, что в данном случае у эквивалента в китайском языке отсутствует предлог, либо данная фраза переводится при помощи неглагольных форм. Ср.: В музее Антон долго видел красивую картину / Я фотографироваю в университете / Я часто иду в театр / $\mathrm{AH}$ тон ехал в Петербург в прошлом году / Он много занимается и изучает очень хорошо / Мои друзья изучают в университете / Hamaша учится литературу в университете/ $\mathrm{OH}$ умеет русский язык? Как видно из примеров, в большинстве случаев речь идет об обстоятельстве места;

2. употребления предлога семантически близкого глагола. Данная ошибка, скорее всего, сформирована в результате того, что оба подобных с семантикой глагола переводятся на китайский язык одним значением. В данном случае речь идет о потере валентностного элемента, но при этом присутствует другой элемент, который по валентности может быть: а) вторым элементом; б) валентным для глагола, смысл которого близок к неправильно употребленному глаголу. В этой комнате можно смотрю телевизор? /Завтра мы будем ходить в бассейн.

По формальным признакам наблюдается и нередкое совмещение конструктивной ошибки с деструктивной. Они формируются, например, при наличии супплетивных форм. Деструктивная ошибка характерна при субституции глаголов дополнений, в результате чего возникает путаница при глагольной валентности. Ср.: Антон часто сказал по телефон. Деструктивная ошибка характерна также при актуализации категории одушевленность / неодушевленность. Ср.: Что он учится в университете? Отсутствие категории одушевленность / неодушевленность проявляется на уровне конструктивной ошибки, так как деструкт смысла не наступает из-за вербоцентрического свойства русской языковой системы. Ср.: Как зовут площадь в чентре? / Твоего друга называется Петя? / Интересно, почему зовут площадь Красная?

Совмещение конструктивных ошибок с деструктивным на основе субституции характерно и для одной самых проблематичных для освоения категорий - категория глаголов движения. Так, в примерах Саша! Ходи сюда! / Мы часто пойдем в цирк ошибки связаны с неправильным употреблением русских глаголов движения uдmu / ходumb, что свидетельствует о том, для русских глаголов движения релевантным являются семантические признаки однонаправленность / неоднонаправленность, а для китайского языка, напротив, не характерно такое противопоставление, эти признаки заключены В контексте. В китайском языке, спецификой которого является иероглифическое письмо, иероглиф представляет собой не знак, а рисунок, подобный пиктограмме, всегда несущий значение. Значение иероглифа «зоу» включает в себя значение «передвигаться с помощью ног», соответственно в русском языке он может переведен китайцем вариантно: идти, ходить, шагать и т.п. Можно говорить о лексической ошибке, так как мнение, что однонаправленность / разнонаправленность глаголов движения имеет аспектуальный характер, опровергнуто А.В. Исаченко, который пишет, что «разница между глаголами типа идти и ходить не сводится к разнице в видах, так как оба глагола имеют общее грамматическое значение несовершенного вида», соответственно нельзя считать данный факт грамматическим различием [42, с. 13$]$.

Во втором примере, помимо лексической субституции идти / ходить китайским резидентом не учтен признак кратности / некратности - часто, присущий русским глаголам движения. В китайском языке семантический признак кратность / некратность также не эксплицирован в самих глаголах направления движения и не дифференцируется [43]. Употребление формы совершенного вида в данном предложении - специфика китайского языка - указание на успешное завершение действия.

Итак, категоризация оказывает непосредственное влияние на процесс изучения иностранного языка (в частности, русского): обучающийся должен преодолеть один из самых трудных этапов в освоении неродного языка искусственно усвоить категории (в особенности - языковые), отражающие то, что отсутствует в их родном языке. Например, у китайцев при освоении русской глагольной системы, включающей взаимосвязанную видовременную категорию, охватывающую все русские глаголы, а также проявляющиеся в различных формах непостоянные грамматические признаки, такие как лицо, число и род, проблематичным является освоение таких категорий, как аспектуальность, темпоральность и статальность глагола, присутствующих, как показал анализ научной литературы, и в китайском языке, но, имеющих отличное от китайского языка их выражение в речи, а именно синтетическое. Несоответствие отражения в речи базовых категорий глагола приводит к субституции, формируя при этом структурные и (что является более дезориентирующим для процесса коммуникации) деструктивные ошибки. 


\section{ЛИТЕРАТУРА}

1. Болдырев Н.Н. Теоретическое моделирование процессов функциональной категоризации глагола: коллективная монография / под общей ред. Н.Н. Болдырева. Тамбов: Изд-во ТГУ им Г.Р. Державина, 2000. 172 с.

2. Rosh E.H. Principles of Categorization // Cognition and Categorization. Hillsdale. N.Y.: Lawrence Erlbaum, 1978. P. $27-48$.

3. Абишева К.М. Категоризация и ее основные принципы // Вопросы когнитивной лингвистики. Тамбов, 2013. № 2. С. 21-30.

4. Золотухина-Аболина Е.В. «Изнанка языка»: проблема соотношения континуального и дискретного // Epistemology \& Philosophy of Science. 2018. № 2. C. 98-108.

5. Макавчик В.О. Видо-временная категоризация русского глагола в языковом сознании носителей русского языка: автореф. дис. ... канд. филол. наук. Томск, 2004.

6. Петрухина Е.В. Русский глагол: категории вида и времени. М.: Изд-во МАКС Пресс, 2009. 208 с.

7. Бондарко А.В. Вид и время русского глагола. М.: Просвещение, 1971. 239 с.

8. Шелякин М.А. Категория вида и способы действия русского глагола. Теоретические основы. Таллин: Валгус, 1983. 216 с.

9. Косова В.А. Категориальное представление деривационной признаковой семантики русского языка в учении В.А. Богородицкого // Филологические науки. Вопросы теории и практики. 2013. № 8 (26). Ч. 2. С. 96-98.

10. Гловинская М.Я. Многозначность и синонимия в видо-временной системе русского глагола. М.: Ин-т рус. яз. им. Виноградова РАН, 2001. 320 с.

11. Кравченко Н.Н. Когнитивно-семантический анализ глаголов «сидеть», «стоять», «лежать» // Вестник Московского университета. Сер. 9: Филология. 1998. № 5. . . $62-72$.

12. Кубрякова Е.С. Глаголы действия через их когнитивные характеристики // Логический анализ языка. Модели действия. М.: Наука, 1992. С. 84-90.

13. Лебедева Н.Б. Полиситуативность глагольной семантики (на материале русских префиксальных глаголов). Томск: Изд-во Том. ун-та, 1999. 262 с.

14. Плотникова С.В. Высокочастотные глаголы в современном русском языке: лексико-семантическая классификация и регулярная многозначность: автореф. дис. ... канд. филол. наук. Екатеринбург, 2009.

15. Реформатский А.А. Агглютинация и фузия как две тенденции грамматического строения слова // Реформатский А.А. Лингвистика и поэтика. М.: Наука, 1987. С. 52-76.

16. Милославский И.Г. Вид русского глагола как словообразовательная категория // Филологические науки. Научные доклады высшей школы. 1989. № 4. С. 37-44.

17. Тань Аошуан. Проблемы скрытой грамматики: синтаксис, семантика и прагматика языка изолирующего строя (на примере китайского языка). М.: Языки славянской культуры, 2002.896 с.

18. Цзин Байлян. Времена глаголов в китайском языке // Челябинский гуманитарий. 2017. № 41. С. 74-77.

19. Яхонтов С.Е. Категория глагола в китайском языке. Л.: Изд-во ЛГУ, 1957. 181 с.

20. Иванов А.И., Поливанов Е.Д. Грамматика современного китайского языка. М.: Едиториал УРСС, 2003. 304 с.

21. Го Шуфэнь. Типологическое сопоставление особенностей русского и китайского языков // Грамматика разноструктурных языков: сборник научных статей к юбилею профессора В.Ю. Копрова. Воронеж: Изд-во «Наука-Юнипресс», 2011. С. 90-100.

22. Акимова И.И. Выражение аспектуальнотемпоральных характеристик предложения - высказывания средствами русского и китайского языков (контрастивный анализ в целях преподавания русского языка как иностранного в аудитории китайских учащихся в условиях российского вуза) // Вестник Тихоокеанского государственного университета. 2012. № 3 (26). С. 219-228.

23. Пэн Фань. Категоризация вида в грамматике русского и китайского языков // Челябинский гуманитарий. 2017. № 4 (41). С. $67-69$.

24. Ван Сюемэй. Учет аспектуальных и темпоральных различий китайских и русских глаголов при обучении видам глагола в китайской аудитории // Преподаватель XXI век. 2017. № 4. С. 207-213.

25. Маслов Ю.С. Избранные труды: Аспектология. Общее языкознание / сост., ред. А.В. Бондарко, Т.А. Майсак, В.А. Плунгян. М.: Языки славянской культуры, 2004. $840 \mathrm{C}$.

26. Болдырев Н.Н. Перекатегоризация глагола как способ формирования смысла высказывания // Известия АН. Серия литературы и языка. 2001. Т. 60. № 2. C. $40-55$.

27. Ожегов С.И. Словарь русского языка: Ок. 57000 слов / под. ред. докт. филолог. наук проф. Н.Ю. Шведовой. М.: Русский Язык, 1984. 816 с.

28. Блумфилд Л. Язык: монография. М.: Прогресс, 1968. 607 с.

29. Ельмслев Л. Пролегомены к теории языка // Новое в лингвистике. М.: Наука, 1960. Вып. 1. С. 128-200.

30. Кобков В.П. Замещение в английском языке. Новосибирск: Изд-во АН СССР, 1964. 55 с.

31. Морозова И.С. Заместители предложений: на материале русского и английского языков: автореф. дис. ... канд. филол. наук. Пермь, 2006.

32. Шишкарева 0.А. Новообразования как проявления языковой игры: структурно-функциональный аспект (на материале Нижегородской прессы начала XXI века): автореф. дис. ... канд. филол. наук. Нижний Новгород, 2009.

33. Черноватий Л.М. и др. Переклад у наукових дослідженнях представників харківської школи: колективна монографія / за ред. Л.М. Черноватого и др. Вінница: Нова Книга, 2013.568 с.

34. Гирдянис А. Теоретические основы литовской фонологии / пер. с лит. Н.А. Алексеевой и Н.М. Заики; отв. ред. А. В. Андронов. Вильнюс: Еugrimas, 2014. 447 с. 
35. Артюшкина Л.В. Семантический аспект эвфемистической лексики в современном английском языке: автореф. дис. .... канд. филол. наук. М., 2001.

36. Лукин М.Ф. Критерии перехода частей речи в современном русском языке // Филологические науки. 1986. № 3. С. 49-56.

37. Crymes R. Some Systems of Substitution. Correlations in Modern American English. Moulton: The Hague-Paris, 1968. 187 p.

38. Гун Ц. Методы изучения грамматической транспозиции (на материале изучения отыменных предлогов причины в современном русском языке) // Интерактивные и интегративные методы современной филологии: материалы Международной научной конференции, г. Москва, 18-19 сентября 2017. / под общ. ред. С. М. Колесниковой. М.: МПГУ, 2017. С. 18-28.

39. Гусева А.Е., Первак Т.В. Лексическая субституция как прием модификации фразеологизмов в теледискурсе (на материале мокьюментари «Штомберг» // Вестник Московского государственного областного университета. Электронный журнал. Серия: Лингвистика. 2017. № 2. URL: https://evestnik-mgou.ru/ru/ Articles/Doc/805 (дата обращения: 16.06.2020).

40. Комиссаров В.Н. Теория перевода (лингвистические аспекты): Учеб. для ин-тов и фак. иностр. яз. М.: Высшая школа, 1990. 253 с.

41. Mel'ôuk I.A., Clas A., Polguère A. Introduction à la lexicologie explicative et combinatoire. Louvain-la-Neuve: Editions Duculot, 1995. 256 p.

42. Исаченко А.В. Глаголы движения в русском языке // Русский язык в школе. 1961. № 4. С. 12-17.

43. Ду Хунцзюнь. Система приставочных глаголов движения в русском языке в сопоставлении с китайским языком: автореф. дис. ... канд. филол. наук. M., 2010 .

(с) Щелокова Алена Александровна (schelokova@usurt.ru).

Журнал «Современная наука: актуальные проблемы теории и практики»

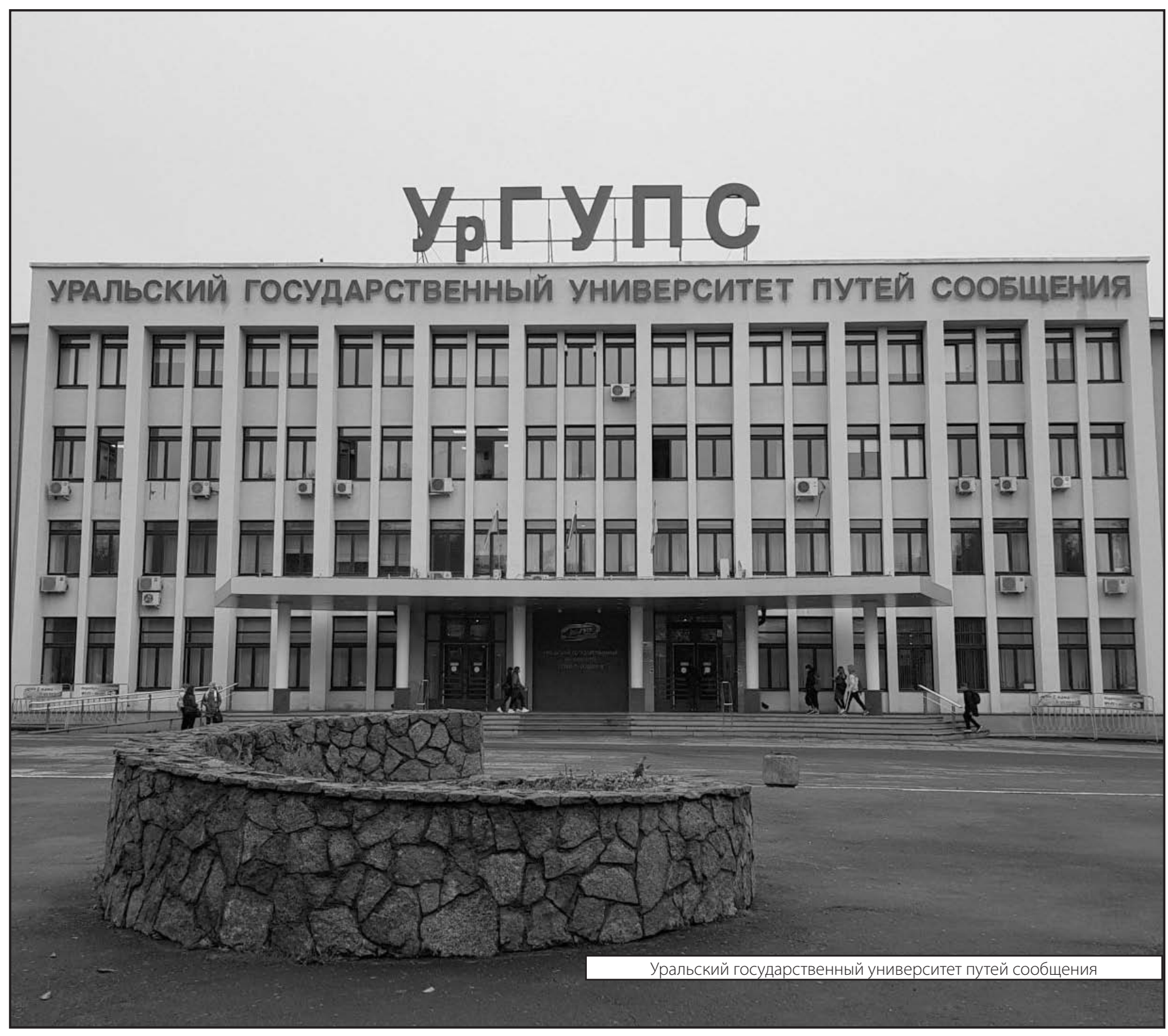

